\title{
The Effects of 3-Dimensional CADD Modeling on the Development of the Spatial Ability of Technology Education Students
}

\author{
K. Lynn Basham and Joe W. Kotrlik
}

\begin{abstract}
Research Framework
Spatial abilities are fundamental to human functioning in the physical world. Spatial reasoning allows people to use concepts of shape, features, and relationships in both concrete and abstact ways, to make and use things in the world, to navigate, and to communicate (Cohen, Hegarty, Keehner \& Montello, 2003; Newcombe \& Huttenlocher, 2000; Turos \& Ervin, 2000). Visualizing intangible boundaries such as state and national borders helps organie, orient, and compartmentalize knowledge of the world. In a similar way, this ability is used to envision new things, and establish relationships of concepts in the mind (Jones \& Bills, 1998). One source estimates that $80 \%$ of jobs primarily depend on spatial ability, not on verbal ability (Bannatyne, 2003). Surgeons, pilots, architects, engineers, mechanics, builders, farmers, trades people, and computer programmers all rely on spatial intelligence (Bannatyne, 2003).

Newcomer, Raudebauch, McKell and Kelly (1999) reported that people who lack spatial ability are not good at interpreting graphic representations, have difficulty with directions and location of things, or are poor at estimating size or visualizing things and their relationships to one another.Yet, these people successfully function because they have more spatial ability than they realize. Spatial ability can be improved in children and adults (Potter \& van der Merwe, 2001; Strong \& Smith, 2001). A potential benefit of improving spatial abilitis is the improvement of academic achievement in mathematics and science (Keller, Washburn-Moses \& Hart, 2002; Mohler, 2001; Olkun, 2003; Robichaux, 2003; Shea, Lubinski \& Benbow, 1992).

Educators debate whether increased spatial aptitude improves performance in science and other subjects (LeClair, 2003). Minimal academic training in science focuses on spatial thinking and most assume the existence of necessary
\end{abstract}

K. Lynn Basham (lynn.basham@doe.virginia.gov) is the Technology Education Specialist with the Virginia Department of Education, Richmond. Joe Kotrlik (kotrlik@1su.edu) is a Professor in Human Resource Education at Louisiana State University. 
spatial skills (Schultz, Huebner, Main \& Porhownik, 2003). It is suspected that spatial ability contributes additional validity to mathematical and verbal reasoning abilities. Gardner (1993) suggested skill in spatial ability determines how far one will progress in the sciences. There is no consensus as to the number of distinct spatial abilities that exist. The two most commonly agreed upon categories are mental rotation and visualization. A third category is usually perception, although some sources nameorientation as the third category (Hegarty \& Waller, 2004; Kaufmann, Steinbug1, Dunser \&Glueck, 2003). Bodner and Guay (1997) portray orientation and visualization as the two major categories as the result of factor analysis of various tests used to measure spatial ability.

\section{Spatial Ability Development}

Several studies indicate that spatial ability can be improved if training with appropriate materials is provided (Cohen et al., 2003; Kinsey, 2003; Newcomer et al., 1999; Potter \& van der Merwe, 2001). Kinsey (2003) found that when university freshmen identified as at risk participated in a session on strategies to improve spatial ability skills, gender differences on the pretest were eliminated as a consequence of the instruction on spatial strategy (Kinsey, 2003). Cohen et al. (2003) found that it is possible to train participants to use mental rotation and perspective by modeling these spatial strategies with animation (Steinke, Huk \& Floto, 2003). In another study, students with low spatial ability spent significantly more time viewing high quality videos and 3-D animations than did students who had high spatial ability (Steinke et al., 2003).

Not all studies indicate that the use of computer software is a significant factor in improving spatial abilities. In a study using 2D and section models, no difference was found between active and passive controls. Shavalier (2004) investigated whether CADD-like software called Virtus Walk Through Pro could be used to enhance spatial abilities of middle school students. No significant difference was found between the control and treatment groups, and no treatment effects were found in measures related to gender or spatial ability levels.

\section{Relationship of Spatial Ability to Mathematical Ability}

Mathematical concepts and relationships are often intangible and are therefore difficult to teach. A relationshiphas been shown between spatial and mathematical ability, and some indicators suggest spatial ability is important for achievement in science and problem solving (Grandin, Peterson \& Shaw, 1998; Keller et al., 2002). Yet, there is little emphasis in the educational system on the development of spatial abilities, perhaps because such abilities are taken for granted or believed to be innate.

\section{Relationship of Spatial Ability to Gender and Ethnicity}

Previous studies indicate a possible relationship between genderand spatial visualization ability (Alias, Black \& Gray, 2002). Some studies indicate that males perform better on spatial rotation tests, but not necessarily on other aspects of 
spatial ability (Grandin et al., 1998; Santacreu, 2004). Bodner and Guay (1997) stated that gender differences often account for only negligible fractions of the variance in spatial ability (Bodner \& Guay, 1997). Although the largest difference was in mental rotation, tests of visualization factors show differences between genders are small or null (Burin, Delgado \& Prieto, 2000). Indeed, meta-analyses reveal that biological factors account for no more thanfive percent of the variability in spatial performance (Schultz et al., 2003). Several studies found that gender was not related to various aspects of spatial ability (Postma, Izendoorn \& De Haan, 1998; Voyer, 1998) while Hubona and Shirah (2004) found relationships between gender and various aspects of spatial ability.

Ritz (2004) found that disparities exist fromethnicity and socioeconomic factors. The largest disparity between African Americans and white students in grade eight is measurement. The gap increased from 40 points in 1990 to 58 points in 2000. A similar gap exists when comparing whites and Latinos (Ritz, 2004).

\section{Background and Significance}

Most ninth grade students in Mississippi take a modular Technology Discovery course that includes a computeraided design and drafting (CADD) module. A characteristic of 3-D CADD modeling is the manipulation of geometric shapes using spatial ability. In order to implement 3-dimensional software in curricula statewide, Pro/Desktop ${ }^{\circledR}$ (2003) was made available through the Design and Technology in Schools Programsponsored by the Parametric Technology Corporation. Evidence did not exist about the effectiveness of using 3dimensional CADD programs to develop spatial ability. This study investigated whether selected instructional methods using 3-dimensional CADD software had an effect on the development of spatial abilities of ninth grade Echnology Discovery students.

\section{Purpose and Research Questions}

The purpose of this study was to determine if there was a difference in the development of the spatial abilities of Mississippi ninth grade Technology Discovery students by instructional treatment as measured by the Purdue Visualization of Rotations Test (PVRT) (Bodner \& Guay, 1997). The research questions were:

1. What are selected characteristics of Technology Discovery students? The characteristics included were gender, ethnicity, coregistration in art, and co-registration in geometry.

2. Do differences exist in the spatial ability development of Technology Discovery students when they are taught using various methods (treatments), when the spatial ability pretest scores are controlled?

3. Do differences exist in the spatial ability development of Technology Discovery students when they are taught using various methods (treatments), when the spatial ability pretest scores, gender, ethnicity, co-registration in art, and co-registration in geometry are controlled? 


\section{Method}

A quasiexperimental design was used for this study. Intact ninth grade Technology Discovery classes were used, with teachers usingPro/Desktop ${ }^{\mathbb{B}}$ 3-D CADD software in a modular setting. The dependent variable was spatial ability as measured by the PVRT. The experimental treatments were as follows:

Teacher and Module (Experimental). This group was taught by the teacher using researcher-developed lesson plans and 3-D CADD modeling software during the design unit, followed by module rotations in which pairs of students used researcher developed, student-directed material to learn more about the 3-D CADD modeling software. Both teacherdirected and studentdirected lessons used 3-D physical models as an aid to instruction.

Module Only (Experimental). This group was taught spatial ability using 3-D CADD modeling software without teacher-directed lessons. Instruction occurred only during module rotations in which pairs of students used researcher developed, student-directed curriculum material in conjunction with 3-D CADD modeling software to develop spatial ability. The lessons utilized 3-D physical models as an aid to instruction.

Existing Material (Experimental). This group was taught spatial ability using 3-dimensional CADD modeling software during module rotations in which pairs of students used the methods and materials that had previously been used by that teacher, with no interventions or changes. It should be noted that a wide variety of materials existed.

No CADD Instruction (Control). This group was not enrolled in Technology Discovery classes and the schools did not offer CADD.

\section{Population and Sample}

Schools that operated on a $4 \times 4$ block schedule and offered Technology Discovery were included in the 3 treatment groups. Students in these schools completed the Technology Discovery course during one semester, with class periods of at least 94 minutes per day. Participating schools with intact classes provided cluster samples. Block schedule schools typically operated three classes per day. Technology Discovery was designed for a maximum class size of 24 students. Each teacher assigned student pairs to instructional module rotations at the beginning of the school year. Each class had the potential of having 12 rotations with two students per rotation.

To avoid researcher bias, schools (with their teachers and students) were randomly assigned to one of three experimental treatments (instructional methods). Teachers located in the same schools were assigned to the same instructional method. The design used a control group from schools not offering CADD. To facilitate consistency, teachers participating in the study received oral and written instructions about study procedures. They were contacted at least two times by telephone and email priorto beginning the study. Instructional 
materials, tests, information forms, instructions for test administration, and return envelopes were mailed. Standard consent forms were used to obtain consent from parents or guardians for the students to participatein the study. Table 1 summarizes the instructions provided to each teacher. Usable data were obtained from 464 students by instructional method, as follows: Teacher Instruction with Module - 101 (21.8\%), Module Alone - 164 (35.3\%), Existing Materials - 116 $(25.0 \%)$, and No CADD Instruction (Control Group) - $83(17.9 \%)$.

Table 1

Instructions provided to technology discovery teachers participating in the study.

\begin{tabular}{lccc}
\hline & \multicolumn{3}{c}{ Instructions Provided to Teachers } \\
\cline { 2 - 4 } & $\begin{array}{l}\text { Test admini- } \\
\text { stration, } \\
\text { submission of } \\
\text { data }\end{array}$ & $\begin{array}{l}\text { 3-D student } \\
\text { module material, Teacher } \\
\text { use of physical } \\
\text { models }\end{array}$ & $\begin{array}{l}\text { centered } \\
\text { instruction }\end{array}$ \\
\hline 1- Teacher with module & Yes & Yes & Yes \\
2- Module alone & Yes & Yes & No \\
3 - Existing materials & Yes & No & No \\
4- No CADD & Yes & No & No \\
\hline
\end{tabular}

Note. Verbal and written instructions were provided to each teacher.

Treatment Development

Lesson plans and instructional material were developed by the researcher. The researcher is a certified Pro/Desktop ${ }^{\circledR}$ trainer and highly qualified to develop material for the software. Instructional sessions were developed using PowerPoint. An existing instructional tutorial for Pro/Desktop ${ }^{\circledR}$ CADD software was utilized in the final lesson.

The instructional materials incorporated the recommendations by Kinsey (2003) regarding the need to provide a combination of methods, including3-D physical models, observation, and hands-on computer use while learning to use CADD software. The design also incorporated the recommendations by Roschelle, Pea, Hoadley, Gordin, and Means (2001) who stated computer technologies should enhance student learning when the four factors of active engagement, participation in groups, frequent interaction and feedback, and connections to realworld contexts are kept in mind while designing instruction. Lesson plans for 160 minutes of teacherdirected instruction supported by physical models were designed. The physical models were then locatedat the CADD workstation for student use with the instructional module. Module materials for learning the CADD software and physical models were prepared to support instruction for both the Teacher and Module and Module Alone instructional methods (1 and 2). Student material included rotation of the objects being modeled on the computer. The connection between geometry and engineering drawing (Keller et al., 2002; Lowrie, 1994; Smith, 2001) led to the inclusion of a review of basic geometric shapes and terms in the modular 
instructional materials. The student-directed modular instructional material was developed for approximately 450 minutes of modular instructional time. Both instructional methods 1 and 2 used this material.

Five teachers who were certified as Pro/Desktop ${ }^{\circledR}$ trainers reviewed the material for face validity. These teachers suggested improvementsto the physical models and revisions to the PowerPoint presentation, including wording and the order of the module sessions. These revisions were made prior to dissemination of the materials. The Existing Materials treatment group (3) was instructed to continue to use materials that were in use during the 20042005 school year. These consisted of tutorials utilized in the training of teachers. The No CADD Instruction treatment group (4) used no software and did not study CADD.

\section{Data Collection and Analysis}

Teachers administered the PVRT as a pretest to all Technology Discovery students in their classes near the beginning of the semester, along with a student information sheet that gathered data on gender, ethnicity, and whether they were currently enrolled in art or geometry. The posttest was given 57 school days after each student completed the CADD module rotation. The time between module and posttest was chosen to measure student achievement at aconsistent amount of time after instruction.

The PVRT was used for both the pretest and posttest. It is appropriate for use with adolescents and may be administeredeither in groups or individually. This test is among the spatial tests least likely to be confounded by analytic processing strategies (Bodner \& Guay, 1997). The test measured the ability to visualize the rotation of 3-dimensional objects. The instrument was chosen because of its high correlation with similar instruments measuring visualization that were not cost effective to use. The PVRTinstrument included 30 questions in which an object was pictured in one position and then it was shown in a second image, rotated to a different position. Participants were shown a second object and given five choices, one of which matched the rotation of the example object. They were asked to select the object that showed the same otation as the example for that question. Students had 15 minutes to complete the timed test. Reliability for the PVRT reported by Bodner and Guay (1997) using KR-20 and split half reliability coefficients ranged from .78 to .85 in nine studies that involved samples sizes ranging from 127 to 1,648 .

Teachers assigned students to rotation schedules at the beginning of the semester, using methods prescribed during teacher training for Technology Discovery. They were asked to adjust the rotations to ensure thatno other CADD or Spatial Information Technology module was completed prior to the module under investigation, nor in the week prior to the posttest. Other than the adjustment stated above, their usual assignment procedures for rotations were applied.

Students in the control group (No CADD group) took the PVRT test with a five-week interval between pretest and posttest. Schools in the control group administered the test in ninth grade English I classes in order to provide the 
module under investigation, nor in the week prior to the posttest. Other than the adjustment stated above, their usual assignment procedures for rotations were applied.

Students in the control group (No CADD group) took the PVRT test with a five-week interval between pretest and posttest. Schools in the control group administered the test in ninth grade English I classes in order to provide the appropriate equivalent sample population. English I classes were used because the course was required of all ninth grade students.

The alpha level was set $a$ priori at .05. Descriptive statistics including values and percentages were used to analyze the data for Research Question 1. Analysis of covariance was used for Research Questions 2 and 3. The number of schools in the sample was 14, including 10 schools that offered Technology Discovery and 4 that did not.

\section{Results}

Characteristics of Population

Most of the students in the study were female and white. A higher number of female students were in each of the treatment groups. There were more black male and female students in the No CADD instruction treatment (control) group, and more white male and female students in the other three treatment groups (see Table 2).

Table 2

Ethnic background and gender reported by treatment group

\begin{tabular}{|c|c|c|c|c|c|c|c|c|c|c|c|}
\hline & & \multicolumn{10}{|c|}{ Ethnicity } \\
\hline & & \multicolumn{2}{|c|}{ Black } & \multicolumn{2}{|c|}{ White } & \multicolumn{2}{|c|}{ Hispanic } & \multicolumn{2}{|c|}{ Asian } & \multicolumn{2}{|c|}{ Other } \\
\hline & & $n$ & $\%$ & $n$ & $\%$ & $n$ & $\%$ & $n$ & $\%$ & $n$ & $\%$ \\
\hline $\begin{array}{l}\text { Teacher } \\
\text { Instruction }\end{array}$ & $\mathbf{F}$ & 16 & 29.2 & 35 & 63.6 & 1 & 1.8 & 2 & 3.6 & 1 & 1.8 \\
\hline $\begin{array}{l}\text { \& Module } \\
n=101\end{array}$ & $\mathbf{M}$ & 4 & 7.9 & 41 & 89.1 & 0 & 0.0 & 0 & 0.0 & 1 & 2.2 \\
\hline Module & $\mathbf{F}$ & 25 & 27.8 & 62 & 68.9 & 1 & 1.1 & 0 & 0.0 & 2 & 2.2 \\
\hline$n=164$ & M & 19 & 25.7 & 52 & 70.3 & 2 & 2.7 & 0 & 0.0 & 1 & 1.3 \\
\hline $\begin{array}{l}\text { Existing } \\
\text { Materials }\end{array}$ & $\mathbf{F}$ & 20 & 31.7 & 43 & 68.3 & 18 & 0.0 & 0 & 0.0 & 0 & 0.0 \\
\hline$n=116$ & M & 21 & 39.6 & 30 & 56.6 & 14 & 1.9 & 0 & 0.0 & 1 & 1.9 \\
\hline $\begin{array}{l}\text { No CADD } \\
\text { Instruction }\end{array}$ & F & 26 & 56.5 & 18 & 39.1 & 0 & 0.0 & 1 & 2.2 & 1 & 2.2 \\
\hline $\begin{array}{l}\text { (Control) } \\
n=83 \\
\end{array}$ & $\mathbf{M}$ & 18 & 48.7 & 14 & 37.8 & 1 & 2.7 & 2 & 5.4 & 2 & 5.4 \\
\hline Total & & 149 & 32.1 & 295 & 63.6 & 6 & 1.3 & 5 & 1.1 & 9 & 1.9 \\
\hline
\end{tabular}

There were 61 (13.1\%) students enrolled in art, 48 (10.3\%) enrolled in geometry, and 17 (3.4\%) students enrolled in both art and geometry. The 
Vol. 20 No. 1, Fall 2008

Table 3

Participants co-enrolled in art and/or geometry by treatment group

\begin{tabular}{|c|c|c|c|c|c|}
\hline \multirow[b]{2}{*}{ Courses } & \multicolumn{4}{|c|}{ Treatment Group } & \multirow[b]{2}{*}{$\begin{array}{c}\text { Totals } \\
\% \\
(N) \\
\end{array}$} \\
\hline & $\begin{array}{c}\text { Teacher } \\
\text { Instruction } \\
\text { and Module } \\
\% \\
\text { (n) }\end{array}$ & $\begin{array}{c}\text { Module } \\
\text { Alone } \\
\% \\
\text { (n) }\end{array}$ & $\begin{array}{c}\text { Existing } \\
\text { Materials } \\
\% \\
\text { (n) }\end{array}$ & $\begin{array}{c}\text { No CADD } \\
\text { Instruction } \\
\% \\
(n)\end{array}$ & \\
\hline No Art or & 52.5 & 81.2 & 81.0 & 71.1 & 73.0 \\
\hline Geometry & (53) & (133) & (94) & (59) & (339) \\
\hline \multirow[t]{2}{*}{ Art } & 16.8 & 14.6 & 12.1 & 7.2 & 13.2 \\
\hline & (17) & (24) & (14) & (6) & (61) \\
\hline \multirow[t]{2}{*}{ Geometry } & 23.8 & 2.4 & 6.0 & 15.7 & 10.3 \\
\hline & (24) & (4) & (7) & (13) & $(48)$ \\
\hline Both Art & 6.9 & 1.8 & 0.9 & 6.0 & 3.5 \\
\hline Geom. & (7) & (3) & (1) & (5) & (16) \\
\hline \multirow[t]{2}{*}{ Total } & 100.0 & 100.0 & 100.0 & 100.0 & 100.0 \\
\hline & (101) & (164) & (116) & $(83)$ & $(464)$ \\
\hline
\end{tabular}

Differences in Spatial Ability Posttest Achievement with Pretest Covariate

Research Question 2 asked if differences existed in spatial ability test scores of Technology Discovery students as measured by the PVRT, when the pretest scores were controlled, and students were instructed using differing treatments (instructional methods). An analysis of covariance (ANCOVA) was conducted to determine if there was a difference in student achievement among the instructional methods. The independent variable of instructional treatment included the four levels described in the research question. The dependent variable was the posttest, the covariate was the pretest, and the fixed factor for the analysis was the instructional method.

The preliminary analysis using Levene's Test revealed that the variances in the posttest scores did not differ among the treatments $\left.F_{(3,460)}=.71 ; p=.548\right)$. Therefore, equal variance across treatment groups was assumed. In addition, a model lack-of-fit test was conducted to determine if there was evidence that the effects of the treatments were nonlinear. The nonsignificant results of the lackof-fit test $\left.\left(F_{(88,368}\right)=1.25 ; p=.086\right)$ indicated that the effects were likely linear. In addition, the interaction between the method factor and the pretest covariate was not significant, $\left(F_{(3,456)}=1.83, p>.05\right)$, indicating that the differences on the posttest among groups did not vary as a function of the covariate. Therefore, the pretest was an appropriate covariate in the analysis of covariance.

Significant differences existed among the means by instructional method $\left(F_{(3,459)}=6.6, p<.001\right.$, partial $\left.e t a^{2}=.04\right)$ (see Table 4). According to Green and Salkind (2003) the partial eta ${ }^{2}$ level of .09 indicates a moderate relationship between posttest scores and teaching methods, with pretest scores as the covariate. Table 5 presents the unadjusted and adjusted means of posttest scores for each instructional method and the control group with the covariate 
included. The adjusted mean for the Teacher Instruction andthe Module groups is larger than the adjusted means for the other instructional treatment grous and the control group. The pairwise comparison conducted using the Bonferroni procedure revealed that the test scores for the Teacher Instruction and Mdule group were significantly higher than the other three groups.

Table 4.

ANCOVA test for differences among treatment means with pretest covariate

\begin{tabular}{lrrrrrr}
\hline Source & $\boldsymbol{S S}$ & $\boldsymbol{d} \boldsymbol{f}$ & $\boldsymbol{M S}$ & $\boldsymbol{F}$ & $\boldsymbol{p}$ & $\begin{array}{c}\text { Partial } \\
\boldsymbol{e t a}^{2}\end{array}$ \\
\hline $\begin{array}{l}\text { Corrected } \\
\text { Model }\end{array}$ & 9317.53 & 4 & 2329.38 & 141.59 & $<.001$ & .55 \\
$\begin{array}{l}\text { Intercept } \\
\text { Instructional }\end{array}$ & 76170.31 & 1 & 76170.31 & 4630.04 & $<.001$ & .91 \\
Method & 741.58 & 3 & 247.19 & 15.03 & $<.001$ & .09 \\
Pretest & 8575.95 & 1 & 8575.95 & 521.29 & $<.001$ & .53 \\
Error & 7551.16 & 459 & 16.45 & & & \\
$\begin{array}{l}\text { Total } \\
\text { Corrected }\end{array}$ & 93039.00 & 464 & & & & \\
Total & 16868.69 & 463 & & & & \\
\hline Note. $R^{2}=.55\left(\right.$ Adjusted $\left.R^{2}=.55\right)$. & & & &
\end{tabular}

Note. $R^{2}=.55$ (Adjusted $R^{2}=.55$ ).

Differences in Spatial Ability Posttest Achievement with Multiple Covariates

Research Question 3 asked if differences existed by treatment (instructional method) in the spatial ability of Technology Discovery students as measured using the PVRT when spatial ability pretest scores are controlled, and explanatory factors of gender, ethnicity, co-regis tration in either art and/or geometry are added to the model. Analysis of covariance with simple contrasts for the explanatory factors was conducted to analyze the data for this research question. The dependent variable was the posttest score; the covariat was the pretest score, and additional explanatory factors were gender, ethnicity, $\mathrm{c} \Theta$ enrollment in art, and co-enrollment in geometry. The fixed factor was the instructional treatment method. Gender was not significantly correlated to the dependent variable posttest scores; therefore, gender was not included in the analysis. 
Table 5

Posttest unadjusted and adjusted mean student scores by instructional method with pretest covariate

\begin{tabular}{lccccc}
\hline \multicolumn{1}{c}{ Instructional Method } & \multicolumn{3}{c}{ Unadjusted } & \multicolumn{2}{c}{ Adjusted } \\
Teacher Instruction and Module & \multicolumn{1}{c}{$\boldsymbol{n}$} & $\boldsymbol{M}$ & $\boldsymbol{S D}$ & $\boldsymbol{M}$ & $\boldsymbol{S} \boldsymbol{D}$ \\
Module Alone & 164 & 15.01 & 5.97 & $14.38^{\mathrm{a}}$ & .41 \\
Existing Materials & 116 & 11.37 & 5.87 & $12.30^{\mathrm{a}}$ & .32 \\
No CADD Instruction & 83 & 12.66 & 6.83 & $11.97^{\mathrm{a}}$ & .45 \\
Totals & 464 & & & & \\
\hline
\end{tabular}

${ }^{\mathrm{a}}$ Covariate in the model is evaluated with pretest value of 11.49 .

An analysis was conducted to determine if the variances in the posttest scores were equal among the treatment groups when the fixed factors were included. The non-significant Levene's Test $\left(F_{(3,460)}=1.11 ; p=.344\right)$ suggests that the variance of the postest scores was approximately equal for the four treatment groups, and equal variance across treatment groups was assumed. A model lack of fit analysis was conducted and it was not $\operatorname{significant}\left(F_{(212,288)}\right.$

$1.02 ; p=.433)$.

An initial ANCOVA tested for the interaction effects. The interaction between the dependent variable posttest and covariate pretest was not significant. Interaction between the dependent variable posttest and ethnicity was not significant, nor was interaction between posttest and ceenrollment in either art or geometry. Since no significant interactions existed, the interaction effects were removed from the ANCOVA prior to conducting the final analysis. Table 6 reports the final analysis of covariance. This analysis resulted in a significant outcome for instructional method $\left(F_{(3,455)}=15.02, p<.001\right)$. The strength of the differences between the fixed factor instructional method and the dependent variable posttest was moderate as indicated by a partialeta ${ }^{2}$ of .09 (Green \& Salkind, 2003). It is interesting to note that the partialeta ${ }^{2}$ in this analysis was the same as the result presented for research question 2.

Table 7 presents the unadjusted and adjusted means of posttest scores for each instructional treatment and the control group. Theadjusted mean for the Teacher Instruction and Module group is larger than the adjusted means for each of the other instructional treatment groups and also larger than the control group. In order to determine whether the difference in means was statisticaly significant, further analysis using the Bonferronipost hoc procedure was conducted which confirmed that the mean scores for students in theTeacher Instruction and Module group were significantly higher than the other three groups. 
Table 6.

Analysis of Covariance for Differences among Posttests by Instructional Method Groups with Pretest Covariate and Explanatory Factors

\begin{tabular}{lcccccc}
\hline \multicolumn{1}{c}{ Source } & SS & $\boldsymbol{d} \boldsymbol{f}$ & $\boldsymbol{M S}$ & $\boldsymbol{F}$ & $\boldsymbol{p}$ & $\boldsymbol{e t a}^{2}$ \\
\hline $\begin{array}{l}\text { Pretest } \\
\text { Method }\end{array}$ & 8575.95 & 1 & 8575.95 & 521.10 & $<.001$ & $.53^{\prime}$ \\
$\begin{array}{l}\text { ' } \\
\text { Ethnicity-white }\end{array}$ & 741.58 & 3 & 247.19 & 15.02 & $<.001$ & $.09^{\prime}$ \\
' & 27.07 & 1 & 27.07 & 1.65 & .200 & $<.01^{\prime}$ \\
$\begin{array}{l}\text { Ethnicity-black } \\
\text { Co-enrollment ' } \\
\text { in Art }\end{array}$ & 8.83 & 1 & 8.83 & .54 & .464 & $<.01^{\prime}$ \\
$\begin{array}{l}\text { Co-enrollment ' } \\
\text { in Geometry }\end{array}$ & 13.91 & 1 & 13.91 & .85 & .358 & $<.01^{\prime}$ \\
' & 3.25 & 1 & 13.25 & .81 & .370 & $<.01^{\prime}$ \\
$\begin{array}{l}\text { Error } \\
\text { ' }\end{array}$ & 7488.11 & 455 & 16.46 & & & \\
$\begin{array}{l}\text { Total } \\
\left.R^{2}=.56 \text { (Adjusted } R^{2}=.55\right) .\end{array}$ & & & & & & \\
\end{tabular}

\section{Conclusions and Discussion}

In this sample, less than $30 \%$ of Technology Discovery students are black; fewer than 5\% are Hispanic, Asian, or other ethnic backgrounds; and nearly $70 \%$, are white. Since Mississippi public schools average slightly more than 50\% black students enrolled statewide, the fact that less than $30 \%$ of the students in the classes were black is unusual. Over half of the Technology Discovery students are female. Both black and white females outnumber black and white males in the classes. Few Technology Discovery students enrolled in art or geometry.

Table 7

Posttest Unadjusted and Adjusted Mean Scoresof Students by Instructional Method

\begin{tabular}{lccccc}
\hline \multicolumn{1}{c}{ Instructional Method } & $\boldsymbol{n}$ & $\boldsymbol{M}$ & $\boldsymbol{S D}$ & $\boldsymbol{M}$ & $\boldsymbol{S} \boldsymbol{E}$ \\
\hline Teacher Instruction \& Module & 101 & 15.01 & 5.97 & $14.19^{\mathrm{a}}$ & .42 \\
Module Alone & 164 & 12.55 & 5.41 & $12.61^{\mathrm{a}}$ & .32 \\
Existing Materials & 116 & 11.37 & 5.87 & $12.34^{\mathrm{a}}$ & .38 \\
No CADD Instruction & 83 & 12.66 & 6.83 & $12.20^{\mathrm{a}}$ & .46 \\
Totals & 464 & 12.81 & 6.04 & & \\
\hline
\end{tabular}

${ }^{\mathrm{a} C o v a r i a t e s}$ appearing in the model are evaluated at the following values: pretest $=11.49$, Ethnicity-White $=.64$, Ethnicity-Black $=.32$, Geometry Class $=.14$, Art Class $=.17$. 
A difference exists in spatial ability based on the metbd used to instruct students using 3-D CADD modeling software, with the instructional method of Teacher with Module being more effective than either the Module Alone or the Existing Materials method in improving spatial ability achievement scores. This occurred both in the analysis for Research Question 2 where the only covariate was the pretest and in Research Question 3, where gender, ethnicity, coenrollment in art and co-enrollment in geometry were included as covariates. It can be concluded that theuse of 3-dimensional CADD modeling software affects student spatial ability development when a combination of teacherlead and student-directed instruction is used with 3-dimensional physical models.

The teacher-led lesson was the likely factor explaining the Teacher with Module group's gain in spatial ability. Roschelle et al. (2001) stated that social contexts such as teacherdirected group lessons give students the opportunity to successfully perform more complex skills than they could manage alone. Working on a task with others not only provides opportunities to replicate what others are doing, but also to discuss the task and ideas involved.

No difference was found among the spatial ability of students who studied CADD using the Module Alone method, the Existing Materials method, and students who did not study CADD at all. This occurred both in the analysis for Research Question 2, where the only covariate was the pretest and in Research Question 3, where gender, ethnicity, co-enrollment in art and co-enrollment in geometry were entered as covariates. The instructional methods Module Alone and Existing Materials were both based on selfdirected student learning.

A cursory review of test scores indicated that some students appeared to gain in the ability to mentally rotate an object. Others showed little or no gain. There may be a connection between this and the study done by Battista (2002) which cited the theory of constructivism as a basis for instructional design for teaching mathematics. The theory proposes that to understand new ideas, students must personally construct meaning using their own knowledge and reasoning. Though student-directed modular learning is based on this theory, it was not supported by this study. Student use of modules was ond effective in increasing the spatial ability to mentally rotate objects when the teacher established a common understanding of the views used in the software prior to modular instruction. Various factors may account for the lack of gain in the Module Alone and Existing Materials groups. Due to the typical teacher centered learning environment with which students are familiar, they may not consider instruction that is studentdirected to be as important as traditional instruction. Constructivist learning theory suggests that by reflecting on experiences, students construct their own understanding of the world. In order for students to learn in this manner, they must actively participate in the planned activities of a lesson. In a modular learning environment some students may not seriously concentrate on the lessons provided, considering themselves as passive learners responsible only for material that is presented by teachersfor which they expect to be tested. Although multimedia has been relatively successful as a learning tool, it is not enoughby itself to guarantee that students 
will actually learn. The exclusive use of multimedia is intriguing, but it doesnot necessarily require the learner to be in active control of the learning process or necessarily thinking about what is being presented (Mohler 2001). In addition, if two students are working at a learningstation and only one computer is available, one of the pairmay dominate the interaction with the software. The passive student may not take responsibility for her or his learning, allowing a partner to interact more with the software. When students are placed in the relatively passive role of receiving information, they often fail to develop sufficient understanding to be able to apply what they have learned to other situations (Roschelle et al, 2001).

Moreover, hands-on manipulations may divert the short-term memory resources of some students, reducing the possibility of comprehending the simultaneous manipulation of a larger number of mental elements (Smith, 2001). In addition, Steinke et al. (2003) found that some students required observation with no activity in order to process new concepts.

\section{Recommendations for Future Research}

Based on the findings of this study and the review of literature,one can conclude that little is known about how the use of Computer Aided Design and Drafting technology affects student spatial ability development. Continued research in this area is both vital and needed. Replication of this study in other states would contribute to the research and knowledge base for both CADD instruction and spatial ability improvement. Further research is needed to determine whether the conclusions reached in this study would be consistent with other similar studies and, specifically, whether or not a particular instructional method using 3-D CADD modeling is consistent in the improvement of the spatial ability of students. This would contribute to the goal of the National Research Council (2006) to include an emphasis on learning to hink spatially in education systems.

Numerous studies indicate a high correlation between mathematics achievement and spatial ability. Other studies have found that spatial ability affects student achievement in science as well as other subjects. Therefore, research that specifically examines development of spatial ability when using 3-D modeling software should be continued. It is possible that the development of spatial visualization ability could be the most important contribution that technology education could make to learners. Consequently, it could be the most defensible reason for the inclusion of technology education for all students.

\section{References '}

Alias, M., Black, T. R., \& Gray, D. E. (2002). Attitudes towards sketching and drawing and the relationship with spatial visualization ability in engineering students. International Education Journal, 3(3), 165-175.

Bannatyne, A. (2003). Multiple intelligences. Bannatyne Reading Program. Retrieved April 18, 2005, from www.bannatynereadingprogram.com/BP12MULT.htm $92-3$. 
Battista, M. T. (2002). Learning geometry in a dynamic computer environment. Teaching Children Mathematics, 8(6), 333.

Bodner, G. M., \& Guay, R. B. (1997). The Purdue Visualization of Rotations Test. The Chemical Educator, 2(4), 1-18.

Burin, D. I., Delgado, Y. G., \& Prieto, A. R. (2000). Solution strategies and gender differences in spatial visualization tasks. Psicológica, 21, 275-286.

Cohen, C. A., Hegarty, M., Keehner, M., \& Montello, D. R. (2003, July).Spatial ability in the representation of cross sections. Poster presented at the Annual Conference of the Cognitive Science Society Conference, Boston, MA.

Gardner, H. (1993). Multiple intelligences: The theory in practice New York, NY: Basic Books, A Member of the Perseus Books Group.

Grandin, T., Peterson, M., \& Shaw, G. L. (1998). Spatialtemporal versus language-analytic reason. Arts Education Policy Review, 99(6), 11.

Green S. B. \& Salkind, N. J. (2003). Using SPSS for Windows and Macintosh: Analyzing and understanding data(3rd ed.). Upper Saddle River, NJ: Prentice Hall.

Hegarty, M., \& Waller, D. (2004). A dissociation between mental rotation and perspective-taking spatial abilities. Intelligence, 32, 175-191.

Hubona, G. S., \& Shirah, G. W. (2004). The gender factor: Performing visualization tasks on computer media. Proceedings, 37th Hawaii International Conference on System Sciences.

Jones, K., \& Bills, C. (1998, June). Visualization, imagery and the development of geometrical reasoning. Geometry Working Group, Retrieved April 10, 2005, from www.soton.ac.uk/ dkj/bsrlmgeom/reports/K_Jones_et_al_June_1998.pdf

Kaufmann, H., Steinbügl ', K., Dünser', A., \& Glück, J. (2003). Improving spatial abilities by geometry education in augmented reality-application and evaluation design. Vienna University of Technology. Retrieved July 25, 2005, from http://www.ims.tuwien.ac.at/publication_detail.php?ims_id=TR188-2-2005-01

Keller, B., Wasburn-Moses, J., \& Hart, E. (2002). Improving students' spatial visualization skills and teachers' pedagogical content knowledge by using on-line curriculum-embedded applets: Overview of a research and development project. Retrieved May 23, 2005, from http://illuminations.nctm.org/reflections/http://illuminations.nctm.org/downl oads/IsoPaperV4.pdf

Kinsey, B. (2003). Design of a CAD integrated physical model rotator. American Society for Engineering Education Annual Conference \& Exposition. University of New Hampshire. Retrieved April 10, 2005, from www.ni.com/academic/journal_asee.htm

LeClair, E. E. (2003). Alphatome--enhancing spatial reasoning. Journal of College Science Teaching, 33(1), 26-31.

Lowrie, T. (1994). Developing talented children's mathematical ability through visual and spatial learning tasks. Australian Association for Research in 
Education. Retrieved March 18, 2005, from http://www.aare.edu.au/92pap/lowrt92487.txt

Mohler, J. L. (2001). Using interactive multimedia technologies to improve student understanding of spatially-dependent engineering concepts. Paper presented at the GraphiCon'2001, Nizhny Novgorod, Russia. September 10$15,2001$.

National Research Council. (2006). Learning to think spatially. Washington, DC: The National Academies Press.

Newcombe, N. S., \& Huttenlocher, J. (2000). Making space: The development of spatial representation and reasoning. Cambridge, MA: The MIT Press.

Newcomer, J. L., Raudebaugh, R. A., McKell, E. K., \& Kelley, D. S. (1999). Visualization, freehand drawing, solid modeling, and design in introductory engineering graphics. Paper presented at the 29th ASEE/IEEE Frontiers in Education Conference, San Juan, Puerto Rico. American Society for Engineering Education/Institute of Electrical and Electronic Engineers. Retrieved March 22, 2005, from http://fie.engrng.pitt.edu/fie99/papers/1006.pdf

Olkun, S. (2003, April 17). Making connections: Improving spatial abilities with engineering drawing activities. International Journal of Mathematics Teaching and Learning. Retrieved March 18, 2005, from http://www.cimt.plymouth.ac.uk/journal/default.htm

Postma, A., Izendoorn, R., \& De Haan, E. H. F. (1998). Sex differences in object location memory. Brain and Cognition, 36,334-345.

Potter, C., \& van der Merwe, E. (2001). Spatial ability, visual imagery and academic performance in engineering graphics. Paper presented at the International Conference on Engineering Education, Oslo, Norway.

Pro/Desktop (Version 8) [Computer software]. Needham, MA: Parametric Technology Corporation.

Ritz, J. M. (2004, May/June). Technology education-a resource for teaching mathematics: Standards-based testing a major issue impacting public education. The Technology Teacher, 63(8), 20-24.

Robichaux, R. R. (2003). The improvement of spatial visualization: A case study. Journal of Integrative Psychology, 4(2). Retrieved May 23, 2005, from http://www.integrativepsychology.org/articles/vol2_article3.htm

Roschelle, J., Pea, R., Hoadley, C., Gordin, D., \& Means, B. (2001). Changing how and what children learn in school with computerbased technologies. The Future of Children, 10(2), 76-101.

Santacreu, J. (2004). Sex differences in verbal reasoning are mediated by sex differences in spatial ability. The Psychological Record, 54(3). Retrieved March 8, 2005, from http://www.findarticles.com/p/articles/mi_qa3645/is_200407/ai_n9435821

Shavalier, M. (2004). The effects of CAD-like software on the spatial ability of middle school students. Journal of Educational Computing Research, 31(1), 37-49. 
Schultz, K., Huebner, J., Main, K., \& Porhownik, N. (2003). Spatial performance and women's persistence and success in science. University of Winnipeg, Manitoba, Canada. Retrieved 5-5-2005, from http://www.mun.ca/cwse/Schultz,Katherine.pdf

Shea, D. L., Lubinski, D., \& Benbow, C. (2001). Importance of assessing spatial ability in intellectually talented young adolescents: A 20-year longitudinal study. Journal of Educational Psychology, 95(3), 603-614.

Smith, G. G. (2001). Interaction evokes reflection: Learning efficiency in spatial visualization. Interactive Multimedia: Electronic Journal of ComputerEnhanced Learning. Retrieved May 23, 2005, from http://imej.wfu.edu/articles/2001/2/05/index.asp

Steinke, M., Huk, T., \& Floto, C. (2003). The use of high quality 3D animations and videos in hypermedia systems by learners with different cognitive abilities. Paper presented at the Proceedings of E-Learn. Retrieved March 8,2005, from http://projekte.13s.unihanover.de/pub/bscw.cgi/d28316/Huk_ELearn2003_Attitude.pdf

Strong, S., \& Smith, R. (2001). Spatial visualization: Fundamentals and trends in engineering graphics. Journal of Industrial Technology, 18(1). Retrieved April 10, 2005, from http://www.nait.org/jit/Articles/strong122001.pdf

Turos, J. M., \& Ervin, A. I. (2000). Training and gender differences on a web based mental rotation task. The Penn State Behrend Psychology Journal, 4(2), 3-12.

Voyer, D. (1998). Mathematics, gender, spatial performance, and cerebral organization: A suppression effect in talented students.Roeper Review, 20(4). Retrieved March 8, 2005, from

http://www.questia.com/PM.qst?a $=$ o\&se $=$ gglsc \&d=5001378119\&er $=$ deny 